\title{
Hierarchical Porous Carbon Microfibers Derived from Tamarind Seed Coat for High-Energy Supercapacitor Application
}

\author{
T. Ramesh, ${ }^{\dagger \neq}$ N. Rajalakshmi, ${ }^{\dagger}{ }^{\dagger}$ 잉. S. Dhathathreyan, ${ }^{\dagger}$ and L. Ram Gopal Reddy ${ }^{\ddagger}$
}

${ }^{\dagger}$ Centre for Fuel Cell Technology, International Advanced Research Centre for Powder Metallurgy and New Materials (ARCI), IIT-M Research Park, Phase 1, II Floor, 6, Kanagam Road, Taramani, Chennai 600113, India

${ }^{*}$ Department of Physics, National Institute of Technology, Warangal 506004, India

Supporting Information

ABSTRACT: The overwhelming interest in supercapacitors has led to the search for various carbonaceous materials, leading to hierarchical porous carbons. Herein, we report a natural biomass (tamarind seed)-based hierarchical porous carbon without any template and activated by a facile scheme. The tamarind seed coat-based hierarchical porous carbon possessed a unique configuration, making the material exhibit superior supercapacitor properties. A single carbon fiber hosting a distinctive micro- and mesoporous structure formed a connecting thread between the pores. This unique structure enabled high surface area and high capacitance. The highest surface area obtained by this method was $1702 \mathrm{~m}^{2} \mathrm{~g}^{-1}$, whereas the capacitance was $157 \mathrm{~F} \mathrm{~g}^{-1}$ in $6 \mathrm{M} \mathrm{KOH}$. Further, an ionic liquid-based electrolyte revealed 78 $\mathrm{F} \mathrm{g}^{-1}$ at a current density of $0.5 \mathrm{~A} \mathrm{~g}^{-1}$. Outstanding capacity retentions of 96 and $93 \%$ were obtained over 1000 cycles at a current density of $2 \mathrm{~A} \mathrm{~g}^{-1}$ for
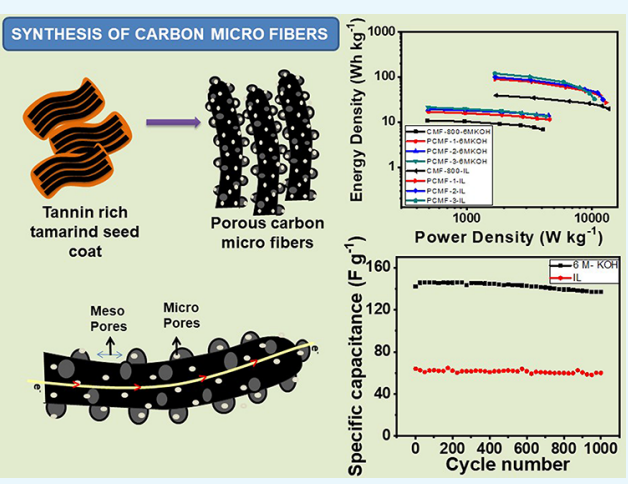
aqueous $(6 \mathrm{M} \mathrm{KOH})$ and ionic liquid (1-butyl 3-methyl imidazoliumbistrifluorosulfonylimide) electrolytes, respectively. The high charge-storage ability of the porous carbon microfibers (PCMFs) can be ascribed to the coexistence of micro- and mesopores. The power characteristics and the cyclic stability of PCMF materials were appealing in both electrolytes. The synthesis process described is amenable for large-scale applications with less complexity.

\section{INTRODUCTION}

Serious environmental and energy crisis has led to an enhanced development of green energy storage. ${ }^{1}$ Supercapacitors (SCs) or electric double-layer capacitors (EDLCs) are highcapacitance commercial secondary energy storage systems with a well-known power density. ${ }^{2}$ Numerous types of materials have been studied for SCs. ${ }^{3-7}$ High-surface-area carbons with excellent electrical conductivity are usually employed as SC electrode materials. These materials exhibited a high electrochemical capacitance but poor rate capability owing to inadequate ionic diffusion and charge-transfer resistance inside the tortuous pores. Therefore, the quest to achieve a high capacitance with novel porous carbon materials with modified and improved morphology is ongoing, and a high power density with capacity retention has not been punctuated to date.

Paving the way to novel morphologies was the advent of hierarchical porous carbon (HPC), considered to be one of the ideal electrode materials for SCs because of their threedimensional (3D) porous channels with a well-balanced micro-, meso-, and macroporous structure. ${ }^{8}$ HPCs are widely synthesized from resorcinol-formaldehyde, ${ }^{9}$ polystyrene, ${ }^{10}$ polypyrrole, ${ }^{11}$ sucrose, ${ }^{12}$ fructose, ${ }^{13}$ glucose, ${ }^{14}$ and cellulose ${ }^{15}$ by template method. Furthermore, the existing template method mostly employs expensive, synthetic, and nongreen route precursor materials along with surfactants that are nonrenewable.

To circumvent these issues, biomass and its derivatives such as cotton, ${ }^{16}$ Metaplexis japonica, ${ }^{17}$ Cyclosorus interruptus, ${ }^{18}$ cotton, hardwood, softwood, bamboo, ${ }^{19}$ rice straw, soybean stalk, wheat straw, corn stalk, rice straw, cotton stalk, and peanut shell ${ }^{20}$ were introduced as precursors for the HPCs. Exemplary synthesis strategies have been reported with these types of biomass precursors to achieve a desired morphology and a well-defined porosity. All the aforementioned carbon materials have been reported to possess a high capacity in electrochemical devices owing to the microporous and mesoporous tuning. ${ }^{16-22}$

To highlight a few such materials with high capacity; Tian et al. developed an HPC derived from bamboo by a hydrothermal method, and the optimized sample exhibited a maximum surface area of $1472 \mathrm{~m}^{2} \mathrm{~g}^{-1}$ and a capacitance of $148 \mathrm{~F} \mathrm{~g}^{-1}$ at a current density of $0.1 \mathrm{~A} \mathrm{~g}^{-1}$ in $6 \mathrm{M} \mathrm{KOH}^{23}$ An interconnected channel like HPC aerogel has been obtained from bagasse by the freeze-drying method and has a maximum surface area of $1892 \mathrm{~m}^{2} \mathrm{~g}^{-1}$ and exhibits a high capacitance of $142 \mathrm{~F} \mathrm{~g}^{-1}$ at a current density of $0.5 \mathrm{~A} \mathrm{~g}^{-1}$. Later, Peng et al. developed a

Received: August 1, 2018

Accepted: September 24, 2018

Published: October 8, 2018 


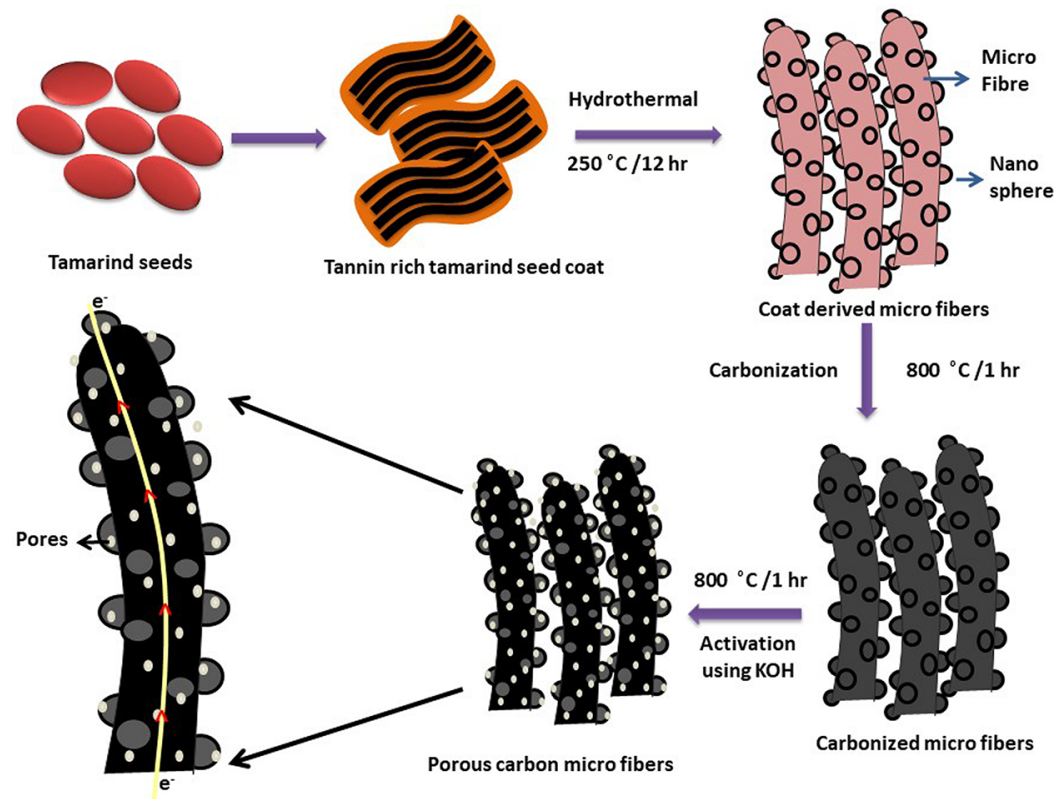

Figure 1. Schematic of hierarchical PCMFs synthesized from tamarind seed coat.

loose porous structured carbon with a well-developed porosity derived from a mixture of sewage sludge and coconut shell as the precursor materials by the hydrothermal method to obtain a super-HPC, which had a surface area of $3003 \mathrm{~m}^{2} \mathrm{~g}^{-1}$, presenting a capacitance value of $62 \mathrm{~F} \mathrm{~g}^{-1}$ at a current density of $0.5 \mathrm{~A} \mathrm{~g}^{-1}$ in a $6 \mathrm{M} \mathrm{KOH} .^{24}$ Recently, Fierro et al. reported an application of tannin-related polyphenol-derived HPCs as SC electrode materials with an excellent capacitance performance $\left(277 \mathrm{~F} \mathrm{~g}^{-1}\right.$ at $0.5 \mathrm{mV} \mathrm{s}{ }^{-1}$ in a three-electrode system), demonstrating a good feasibility to utilize tannin polyphenols to synthesize carbon materials with high electrochemical activity. ${ }^{25}$ It should be emphasized here that a hard template route employing SBA-15 was adopted in the work of Fierro et al.. All the aforementioned materials exhibit high surface area as well as high specific capacitance. However, the synthetic procedure requires rigorous route, which becomes not conducive for large scale.

The efficiency of polyphenols as precursors in achieving a HPC is evident from the number of studies reported so far. $^{26-30}$ Hence, a natural biomass rich in polyphenols with an inherent template was hypothesized to lead to a HPC. Tanninrich tamarind seed (Tamarindus indica $\mathrm{L}$ ) largely available in India, Thailand, Indonesia, Myanmar, and Philippines posed as a candidate material. ${ }^{31}$ The tamarind seed comprises carbon $(\sim 51.7 \%)$, nitrogen $(\sim 35.5 \%)$, and oxygen $(\sim 12.4 \%) .{ }^{31}$ The whole tamarind seed contains $70 \%$ of kernel (white color) and $30 \%$ seed coat or testa (brown). ${ }^{32}$ The seed kernel consists of proteins and polysaccharides widely employed in pet food, textile, mining, and pharmaceutical industries. The seed coat consists of a high portion of fibers, tannin (30-40\%), and dyeing matters which are unsuitable for the food industry. Large quantities of seed coat are obtained from the food industry during the separation process, which are discarded as biowaste.

These generally discarded seed coats possess two salient features making them unique as a precursor. First, tannin contains polyphenolic compounds (phloroglucinol, gallic acid, and catechin) of high molecular weight (about 500-3000), and it is soluble in water and becomes the source of carbon. ${ }^{32}$
Second, the crude fiber contains a lignocellulose highly stable till $300{ }^{\circ} \mathrm{C}$ under hydrothermal conditions. ${ }^{33}$ Therefore, the fibrous structure is expected to be retained even after the hydrothermal process, allowing them to act as a self-template for the formation of microfibers. The particular chemical composition and microstructure of the tamarind seed coat can be utilized to form a hierarchical PCMF without using templates and catalysts by the hydrothermal method. Herein, we demonstrate the preparation of a hierarchical PCMF using tamarind seed by the hydrothermal method. The synthesis strategy to form hierarchical PCMFs from the seed coat is schematically illustrated in Figure 1. This process of making HPC microfibers is simple, economical, and can be easily scaled up. The tuning of micro- and mesopores on the mechanically stable microfibers is essential for electrode applications.

\section{RESULTS AND DISCUSSION}

The macroscopic image of an untreated tamarind seed coat is shown in Figure 2a. The seed coat covers the kernel from any mechanical damage, and the brown-colored seed coat evinces the tannin-rich surface. In Figure $2 b$, an electron microscopic view of the cross section of the seed coat reinforced with numerous interconnected fibers is shown. In general, these fibers that possess a high amount of lignocellulose content after subjecting to hydrothermal treatment were labeled as MF-250, and the resulting morphology in Figure $2 c$ clearly depicts the retainment of the fibrous nature. Further, a high-temperature carbonization at $800{ }^{\circ} \mathrm{C}$ yielded distinct strands of fibers, as seen in Figure 2d, labeled as CMF-800.

The porosity can be tuned on the hierarchical structure by chemical activation using $\mathrm{KOH}$. The effect of $\mathrm{KOH}$ concentration on porosity was studied. In Figure S1a-c, the field emission scanning electron microscopy (FESEM) images of the carbon microfibers which were chemically activated are shown. The fibrous structure was retained after chemical activation, which indicates that the carbonized microfibers were thermally stable. The pores on the sphere surface were observed with an increase in $\mathrm{KOH}$ concentration. The 

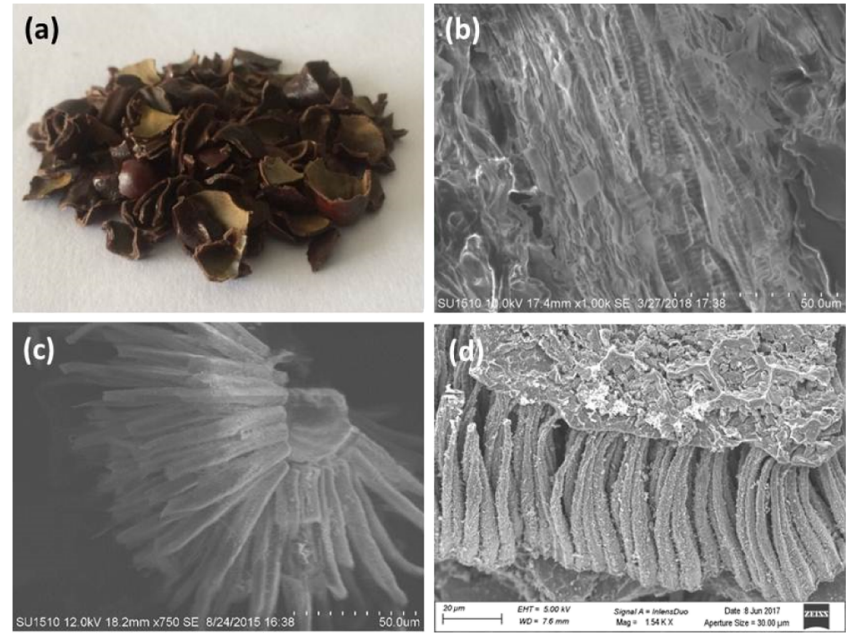

Figure 2. (a) Photograph of a seed coat, (b) SEM cross-sectional image of seed coat, SEM image of (c) MF-250 and (d) FESEM of CMF-800.

chemically activated sample has been labeled as PCMF- $x$ (porous carbon microfibers), where $x$ is $\mathrm{KOH}$ weight ratio.

The samples MF-250 and CMF-800 were further characterized using transmission electron microscopy (TEM) and selected-area electron diffraction (SAED) patterns, as shown in Figure 3, to study the change in morphology and their crystallinity. The TEM analysis of both MF-250 (Figure 3a,b) and CMF-800 (Figure 3d,e) revealed an interconnected network of polygonal nanograins. ${ }^{34,35}$ The average size of the grain was found to be ca. $50 \mathrm{~nm}$. The grains connected to form the fiber undulated with more such grains at irregular intervals in a 3D framework. The SEAD pattern of MF-250 (Figure 3c) was found to be typical of an amorphous material. However, a careful observation of CMF-800 (Figure 3f) revealed three lean diffraction rings around a central bright zone. The SAED pattern evinced the presence of two phases, an ordered phase and a disordered phase, typical of a dual-nature carbon. ${ }^{36}$

The X-ray diffraction (XRD) diffractograms revealed an amorphous structure of MF-250 with characteristic broad peaks at $2 \theta$ values of $15^{\circ}$ and $22^{\circ}$, as presented in Figure S2..$^{37}$
The heat (carbonized)-treated sample exhibited the presence of graphitic planes (002) at $23^{\circ}$ and (100) at $43^{\circ}$, evincing complete carbonization. The XRD results are in good coherence with the SAED pattern. These results indicated that prior to heat treatment the high lignocellulose content dominated the amorphous nature in the sample. ${ }^{38}$ On treatment with concd $\mathrm{KOH}$, the graphitic nature of the sample reduced and the amorphous nature was pronounced, as indicated by the broad peak at $23^{\circ}$ in the diffractograms for PCMF-1 to PCMF-3 seen in Figure S2. The broadening of the peak increased with an increasing concentration of $\mathrm{KOH}$. This could be attributed to the strong etching effect by $\mathrm{KOH}$ over carbon. ${ }^{38,39}$ This etching can produce a significant disorder over the graphitic phase, thereby increasing the functionalities as well as the porous nature of the substrate.

Nitrogen adsorption-desorption curves are used to study the pore characteristics of all the samples. For all of the PCMF samples, type IV isotherm exhibiting H3-type hysteresis loops indicates the presence of micro- and mesoporous structures, as shown in Figure $4 a^{40}$ Moreover, the presence of macropores is indicated as inferred from the sharp increase in the $\mathrm{N}_{2}$ uptake from the isotherm at high relative pressures $\left(P / P_{0}>0.9\right)$. For the samples treated with $\mathrm{KOH}$, the adsorption studies revealed that the surface area increases with an increase in $\mathrm{KOH}$ concentration (Figure 5). The carbonized fibers exhibited 26\% of mesopores because of the space between the interconnected polygonal nanograins. From Figure 5, the influence of chemical activation on the percentage of micro- and mesopores was also studied. The increase in the concentration of $\mathrm{KOH}$ increases the percentage of mesopores that are essential to achieve high specific capacitance.

The abundance of micropore and mesopore surface area is enhanced as a function of $\mathrm{KOH}$ concentration and is tabulated in Table 1. The PCMF-3 sample recorded the highest surface area of $1702 \mathrm{~m}^{2} \mathrm{~g}^{-1}$ with 72 and $28 \%$ of micropores and mesopores, respectively. The optimization of mesopores and micropores is important for supercapacitors to achieve high specific capacitance and high capacity retention. The density functional theory method is used to analyze the pore size distribution and is given in Figure $4 \mathrm{~b}$. From Figure $4 \mathrm{~b}$, large pore volume in the microporous (about $1.7 \mathrm{~nm}$ ) region and
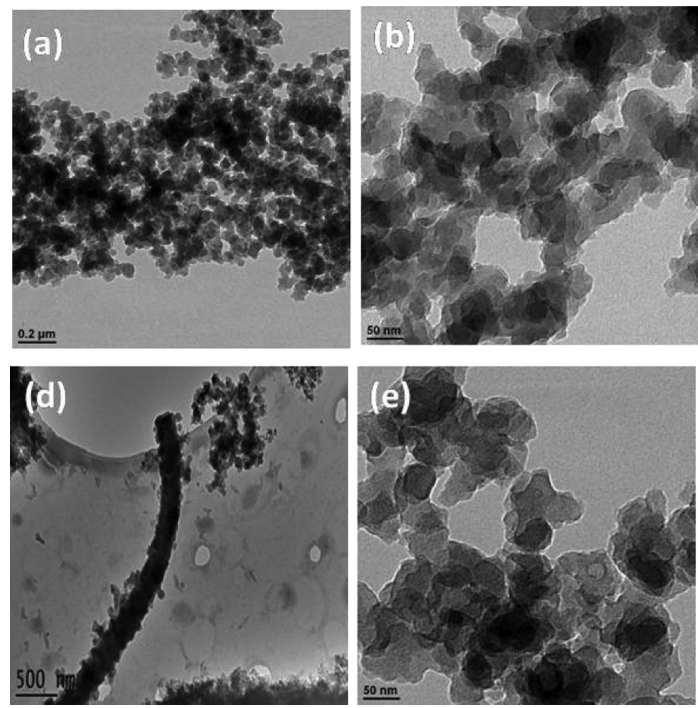
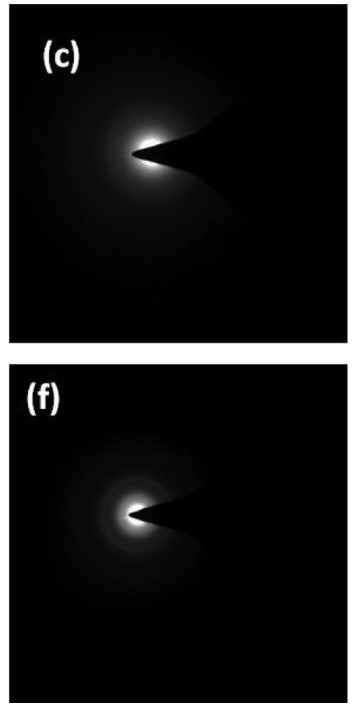

Figure 3. TEM images of MF-250 (a,b) and CMF-800 (d,e); SAED patterns of MF-250 (c) and CMF-800 (f). 
(a)

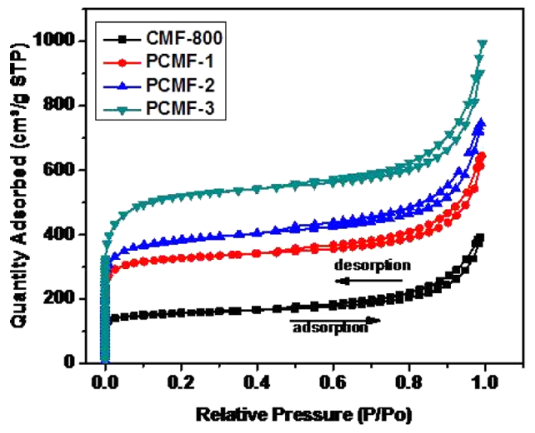

(b)

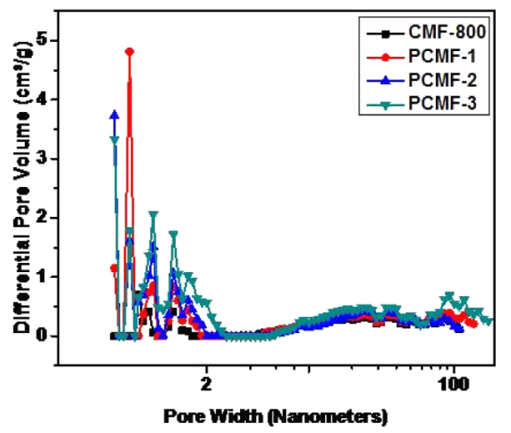

Figure 4. (a) Nitrogen adsorption-desorption isotherms and (b) pore-size distribution.

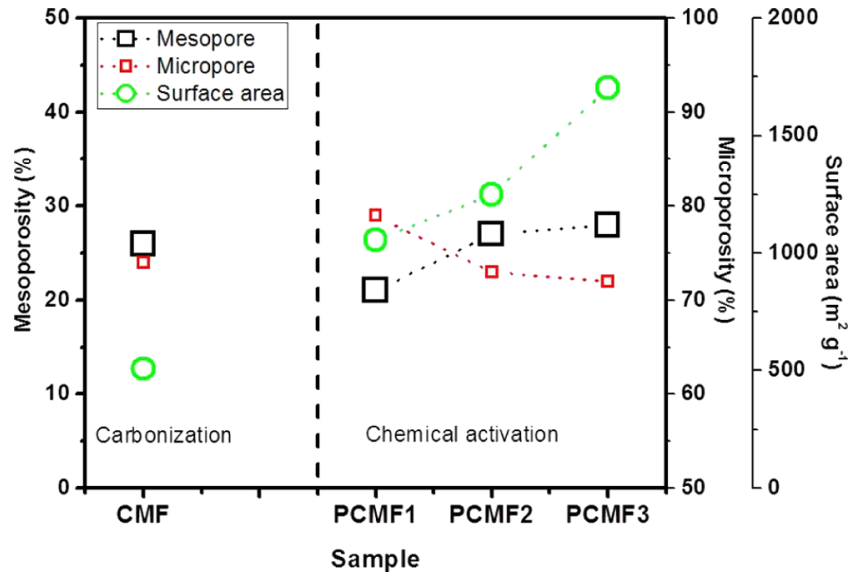

Figure 5. Influence of $\mathrm{KOH}$ concentration on the surface area and the percentage of micropores and mesopores.

Table 1. Pore Parameters of Porous Carbon Microfibers ${ }^{a}$

$\begin{array}{lccccc}\text { sample } & \begin{array}{c}S_{\text {BET }} \\ \left(\mathrm{m}^{2} \mathrm{~g}^{-1}\right)\end{array} & \begin{array}{c}S_{\text {micro }} \\ \left(\mathrm{m}^{2} \mathrm{~g}^{-1}\right)\end{array} & \begin{array}{c}S_{\text {meso }} \\ \left(\mathrm{m}^{2} \mathrm{~g}^{-1}\right)\end{array} & \begin{array}{c}V_{\text {tot }}\left(\mathrm{cm}^{3}\right. \\ \left.\mathrm{g}^{-1}\right)\end{array} & \begin{array}{c}V_{\text {micro }}\left(\mathrm{cm}^{3}\right. \\ \left.\mathrm{g}^{-1}\right)\end{array} \\ \text { CMF } & 508 & 377 & 131 & 0.61 & 0.18 \\ \text { PCMF-1 } & 1056 & 843 & 213 & 0.99 & 0.41 \\ \text { PCMF-2 } & 1250 & 924 & 326 & 1.15 & 0.44 \\ \text { PCMF-3 } & 1702 & 1195 & 507 & 1.53 & 0.58\end{array}$

${ }^{a} S_{\mathrm{BET}}$, specific surface area; $S_{\text {micro, }}$ micropore surface area; $S_{\text {meso }}$, mesopore surface area; $V_{\text {tot }}$ total pore volume; $V_{\text {micro }}$ micropore volume. The values are calculated using the nitrogen adsorptiondesorption isotherm data. less pore volume in the mesoporous (about $2.3-10 \mathrm{~nm}$ ) region were observed. The presence of micropores can effectively enhance the diffusion and mobility of the electrolyte ions to the interior of the electrode and increase the rate capability, whereas the mesopores can accommodate more electrolytes which can effectively enhance the specific capacitance. ${ }^{40,41}$

Electrochemical Performance. Electrochemical characterizations were performed in both aqueous and ionic liquid (IL) electrolytes to understand the influence of ion size on the pore size of the electrode. Figure $6 \mathrm{a}$ shows the cyclic voltammogram of the carbonized and chemically activated samples in $6 \mathrm{M} \mathrm{KOH}$ electrolyte. A characteristic rectangular voltammogram confirmed the EDLC capability of the samples. As anticipated from the surface area data, the material with maximum surface area (PCMF-3; $1702 \mathrm{~m}^{2} \mathrm{~g}^{-1}$ ) exhibited the highest capacitance. The order of capacitance followed the trend observed for the surface area. All the chemically activated samples showed higher capacitance compared to the only carbonized sample (CMF-800). Another significant observation was the marginal reduction in the stable potential window in the activated samples compared to CMF- 800 .

The effect of scan rate on the cycling as well as capacitive behavior of each sample is provided in the Supporting Information (Figure S3). The results were in line with the other results. A comparative plot showing the effect of scan rate on each sample is shown in Figure 6b. Typical to such samples, a gradual drop in capacity was observed with an increasing scan rate. However a very high capacity of approximately $100 \mathrm{~F} \mathrm{~g}^{-1}$ at $200 \mathrm{mV} \mathrm{s}^{-1}$ was retained for PCMF-3.

Galvanostatic charge/discharge (GCD) studies of these PCMF electrodes in a symmetric cell further confirmed the

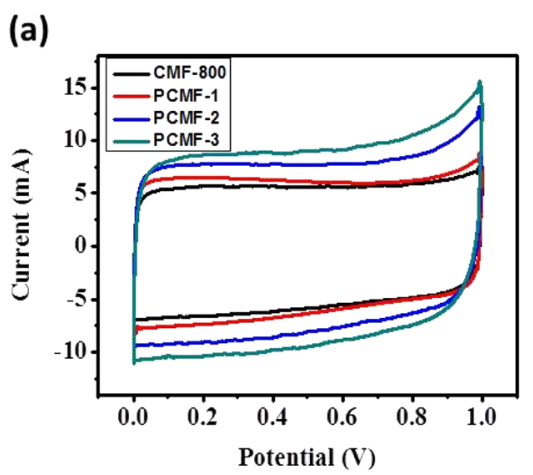

(b)

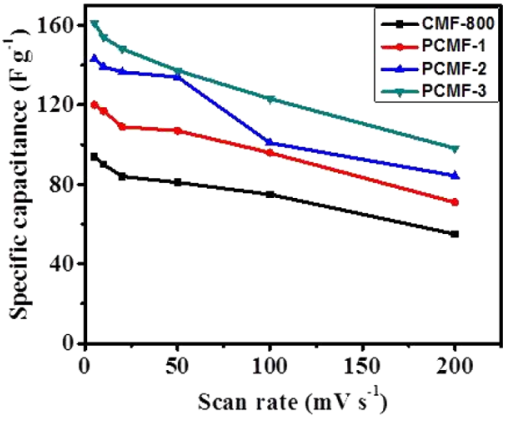

Figure 6. (a) CV curves of PCMF electrodes at a scan rate of $5 \mathrm{mV} \mathrm{s}^{-1}$ in $6 \mathrm{M} \mathrm{KOH}$ electrolyte and (b) specific capacitance of PCMFs at various scan rates. 
(a)

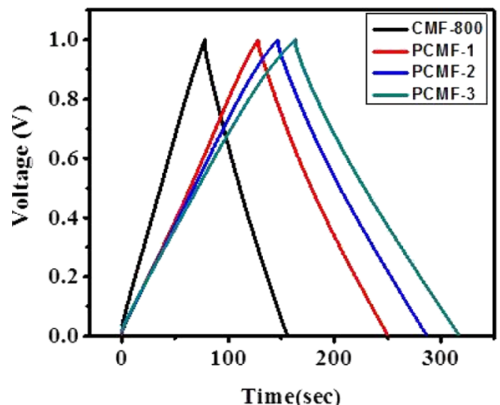

(b)

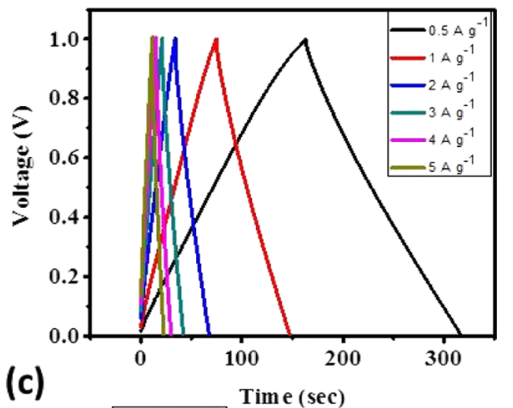

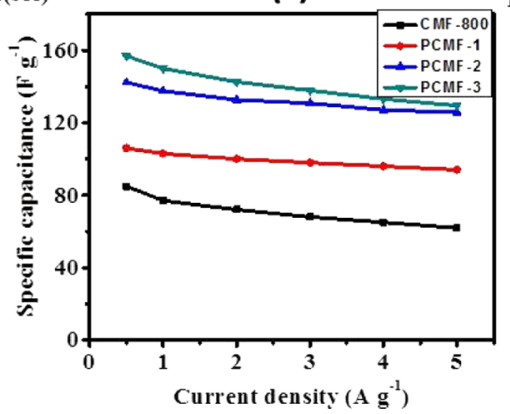

Figure 7. (a) GCD curves of PCMF electrodes at a current density of $0.5 \mathrm{~A} \mathrm{~g}^{-1}$ in $6 \mathrm{M} \mathrm{KOH}$ electrolyte, (b) GCD curves ofPCMF-3 at various current densities, and (c) specific capacitance of PCMFs at different specific currents.

(a)

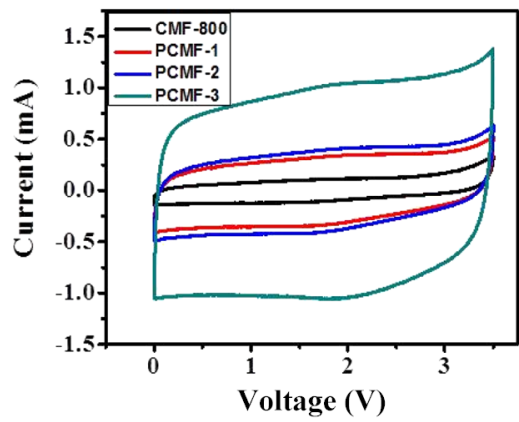

(b)

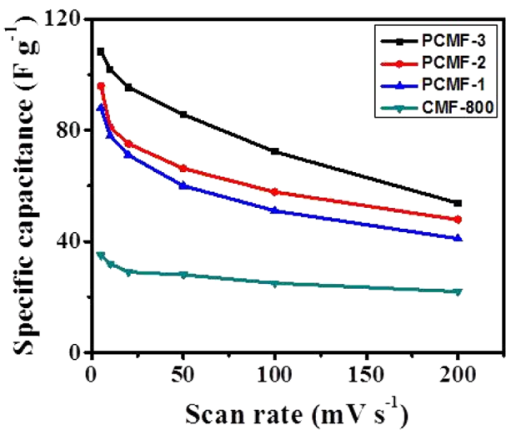

Figure 8. (a) CV curves of PCMF electrodes at a scan rate of $5 \mathrm{mV} \mathrm{s}^{-1}$ in an IL electrolyte and (b) specific capacitance of PCMFs at various scan rates.

high capacitive behavior. The charging and discharging were done in a potential window, that is, the same as that of the CV test, as shown in Figure 7. The PCMF electrode had nearly linear and symmetrical GCD curves, clearly indicating the superior electric double-layer capacitance characteristic and electrochemical reversibility, as well as the fast charge/ discharge behavior, as shown in Figure $7 \mathrm{a}$.

However, the chemically activated samples had an apparently extended discharge time than the carbonized sample, indicating that chemical activation presents a much higher capacitance. The GCD curves of the PCMF-3 electrode are shown in Figure $7 \mathrm{~b}$. The individual GCD curves of the other PCMF electrodes are shown in Figure S4. The curves are almost linear and symmetrical, showing a perfect capacitive behavior. At a current density of $5 \mathrm{~A} \mathrm{~g}^{-1}$, there is a negligible drop in cell voltage, which can be ascribed to the presence of micropores on the one-dimensional structure, permitting quick electron and ion transfers, which is in agreement with the $\mathrm{CV}$ tests. The specific capacitance of the PCMFs has been measured at various current densities and is shown in Figure $7 \mathrm{c}$.
The applications of aqueous electrolyte systems are restricted in terms of energy density as compared to batteries because of their narrow working voltage window $(1 \mathrm{~V})$. The energy density of the system can be improved by the change of an aqueous electrolyte to an IL electrolyte, which has an operating potential of more than $3.5 \mathrm{~V}$. The choice of 1-butyl 3-methyl imidazoliumbistrifluorosulfonylimide (BmIm-TFSI) as an IL was based on its potential window range from 0 to 3.5 V. Also, the selection of the bulky anion in the electrolyte was to understand the influence of electrolyte ion size on the pore size of the electrode.

The cyclic voltammograms in an IL electrolyte exhibited typical rectangular profiles for all the samples and are shown in Figure 8. However, the chemically modified electrode (PCMFs) showed a pronounced increase in pore size evincing increased capacitance. As expected, with an increment in surface area, the specific capacitance also increased. However, the increase in capacitance value between PCMF-2 and PCMF-3 was significantly high.

The effect of scan rate on the cycling as well as capacitive behavior of each sample is provided in the Supporting 


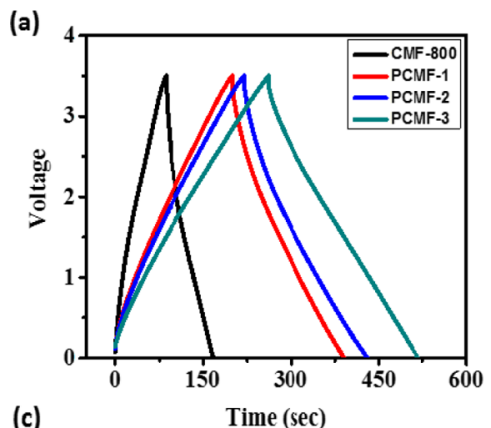

(b)
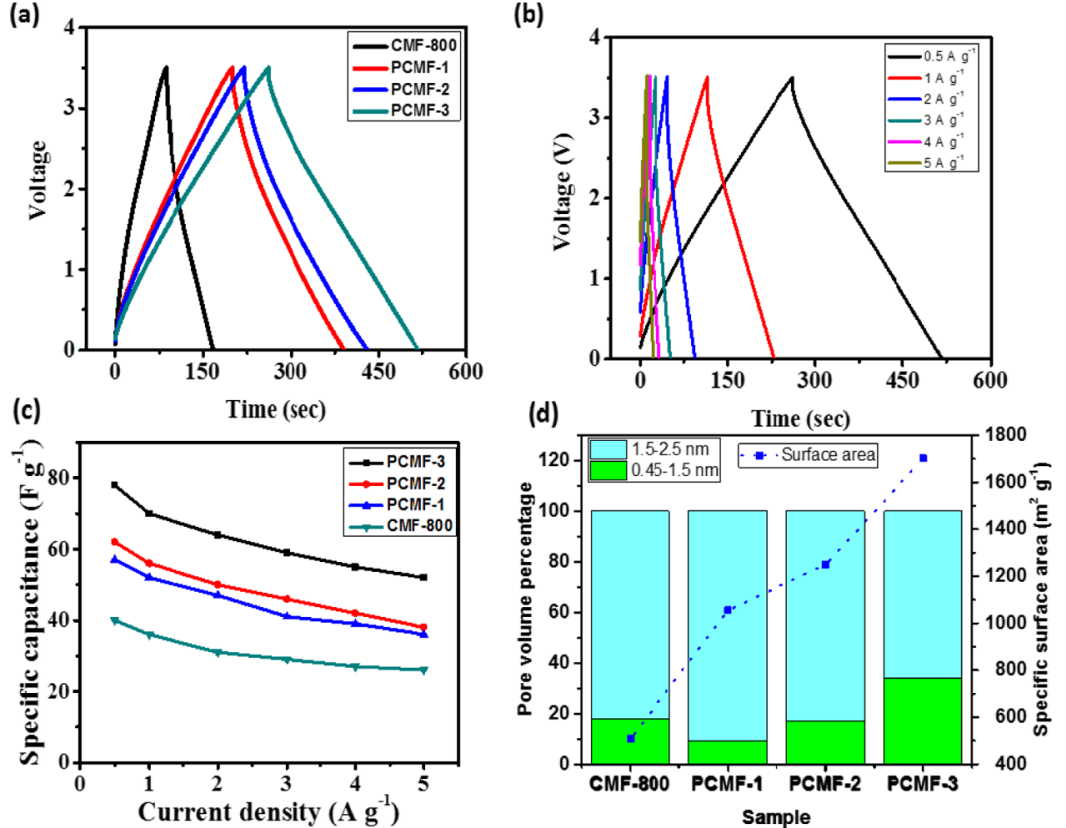

Figure 9. (a) GCD curves of PCMF electrodes at a current density of $0.5 \mathrm{~A} \mathrm{~g}^{-1}$ in BmIm-TFSI electrolyte, (b) GCD curves of PCMF-3 at various current densities, (c) specific capacitance of PCMFs at different specific currents, and (d) percentage of micropore volume vs samples.

Information (Figure S5). At higher scan rates, the voltammograms reflected a pseudocapacitance behavior. Also, one significant attribute of the voltammograms in IL was their lower current density compared to their aqueous counterpart, which can be due to the lower conductivity of IL, especially with the TFSI anions.

GCD was conducted at various current densities of $0.5-5 \mathrm{~A}$ $\mathrm{g}^{-1}$ to evaluate the retention capacity and is shown in Figure 9a. The electrodes exhibited a linear voltage response with respect to time while charging and discharging. The specific capacitance (Figure 9b) of PCMF-3 was calculated to be $76 \mathrm{~F}$ $\mathrm{g}^{-1}$ at $0.5 \mathrm{~A} \mathrm{~g}^{-1}$, and the retention ratios were about $78 \%$ for a scan rate of $5 \mathrm{~A} \mathrm{~g}^{-1}$, which are listed in Table 2. The GCD

Table 2. Specific Capacitance of PCMFs under Different Current Densities

\begin{tabular}{lccccc} 
& \multicolumn{4}{c}{ specific capacitance $\left(\mathrm{F} \mathrm{g}^{-1}\right)$} \\
\cline { 2 - 3 } \cline { 5 - 6 } sample & \multicolumn{2}{c}{$6 \mathrm{M} \mathrm{KOH}$} & & \multicolumn{2}{c}{ BmIm-TFSI } \\
\cline { 2 - 3 } \cline { 5 - 6 } CMF & 82 & $5.0 \mathrm{~A} \mathrm{~g} \mathrm{~g}^{-1}$ & & $0.5 \mathrm{~A} \mathrm{~g}^{-1}$ & $5.0 \mathrm{~A} \mathrm{~g}^{-1}$ \\
PCMF-1 & 124 & 94 & & 40 & 26 \\
PCMF-2 & 142 & 125 & & 62 & 36 \\
PCMF-3 & 157 & 129 & & 78 & 52
\end{tabular}

curves for the other samples are shown in Figure S6. From Figure 9c, the specific capacitance of PCMF-3 was observed to be higher than that of the other samples, which agrees well with the $\mathrm{CV}$ results. The specific capacitance values of the tamarind seed coat-derived HPC are comparable with those of the other biomass-derived carbon electrodes and are listed in Table 3.

Considering the capacitance of PCMF-3 in an aqueous electrolyte, it was evident that the surface area was the only parameter controlling the specific capacitance. However, in case of IL-based systems, the anomalous behavior observed between PCMF-2 and PCMF-3 could be reasoned based on the ionic size of the electrolyte. For instance, in case of BmImTFSI, the ionic size was calculated to be around $0.74 \mathrm{~nm}$. The huge ionic size requires larger pores for a higher capacitance. The pores with sizes in the range of $0.5-1.5 \mathrm{~nm}$ do not provide free access for the ions into the interior portion of the electrode. A pore size more than $1.5 \mathrm{~nm}$ is essential for the free access of IL. PCMF-3, which has $34 \%$ of its micropores in the range of $1.5-2.5 \mathrm{~nm}$, becomes highly suitable for the IL electrolyte. The other samples exhibit lower capacitance not only because of the lower surface area but also because of the lack of sufficient pores with the size in the range of $1.5-2.5$ nm.

Table 3. Comparison of Specific Capacitance of HPC Derived from Tamarind Seed Coat with Other Biomass-Derived Carbon

\begin{tabular}{|c|c|c|c|c|c|}
\hline raw material & surface area $\left(\mathrm{m}^{2} \mathrm{~g}^{-1}\right)$ & specific capacitance $\left(\mathrm{F} \mathrm{g}^{-1}\right)$ & electrolyte/cell system & current density $\left(\mathrm{A} \mathrm{g}^{-1}\right)$ & references \\
\hline coconut shell + sewage sludge & 3003 & 62 & $6 \mathrm{M} \mathrm{KOH} / 2$ electrode & 0.5 & 24 \\
\hline corn cob & 1210 & 120 & $6 \mathrm{M} \mathrm{KOH}$ & 1 & 43 \\
\hline bagasse & 1892 & 142 & $6 \mathrm{M} \mathrm{KOH} / 2$ electrode & 0.5 & 8 \\
\hline bamboo-industrial waste & 1472 & 148 & $6 \mathrm{M} \mathrm{KOH} / 2$ electrode & 0.1 & 23 \\
\hline potato starch & 456 & 245 & $1 \mathrm{M} \mathrm{KOH} / 3$ electrode & 1 & 45 \\
\hline carrageenan & 2502 & 261 & $6 \mathrm{M} \mathrm{KOH} / 3$ electrode & 0.5 & 38 \\
\hline tannin-polyphenol & 1006 & $\sim 196$ & $1 \mathrm{M} \mathrm{H}_{2} \mathrm{SO}_{4} / 3$ electrode & 0.1 & 25 \\
\hline tamarind seed coat & 1702 & 157 & $6 \mathrm{M} \mathrm{KOH} / 2$ electrode & 0.5 & present Study \\
\hline
\end{tabular}


(a)

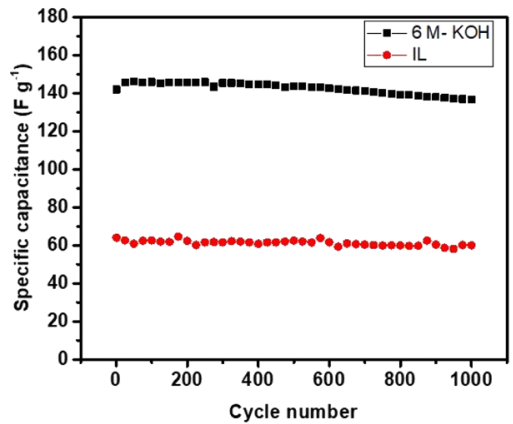

(b)

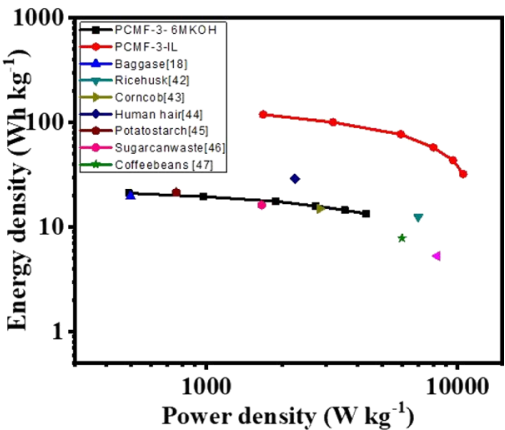

Figure 10. (a) Long-term cyclic stability test of the PCMF-3 electrode at a current density of $2 \mathrm{~A} \mathrm{~g}^{-1}$ in both $6 \mathrm{M} \mathrm{KOH}$ and BmIm-TFSI and (b) power characteristics of PCMF-3 in comparison with the other reported samples.

The cyclic stability is one of the key factors for the SC device application. The cyclic stability of the PCMF-3 electrode has been performed in both $6 \mathrm{M} \mathrm{KOH}$ and the BmIm-TFSI electrolyte over upto 1000 cycles. After 1000 cycles of consecutive charge/discharge at $2 \mathrm{~A} \mathrm{~g}^{-1}$ (Figure 10a), the specific capacitance of the PCMF-3 electrode was maintained to be $136 \mathrm{~F} \mathrm{~g}^{-1}$ for $6 \mathrm{M} \mathrm{KOH}$ and $59 \mathrm{~F} \mathrm{~g}^{-1}$ for BmIm-TFSI, which corresponds to 96 and $93 \%$ of its initial value. The PCMF-3 electrode shows a good cyclic stability in both the electrolytes.

The PCMF-based symmetric SCs were calculated for its energy density and power density. The calculated values were plotted in comparison with the other notable reported biomass-derived carbons and are shown in Figure 10b. In an aqueous system, the energy density of PCMFs ranges from 10.7 to $21.1 \mathrm{~W} \mathrm{~h} \mathrm{~kg}^{-1}$ at $0.5 \mathrm{~A} \mathrm{~g}^{-1}$. The PCMF-3 electrode still retains an energy density of $13.4 \mathrm{~W} \mathrm{~h} \mathrm{~kg}^{-1}$ with a high power density of $4.3 \mathrm{~W} \mathrm{~kg}^{-1}$. The achieved energy density values are similar to the reported values for HPC derived from bagasse, ${ }^{8}$ rice husk, ${ }^{42}$ corn cob, ${ }^{43}$ human hair, ${ }^{44}$ potato starch, ${ }^{45}$ sugarcane waste, ${ }^{46}$ and coffee ground. ${ }^{47}$ The maximum energy density of the PCMF-3 electrode in BmIm-TFSI was found to be $119.2 \mathrm{~W} \mathrm{~h} \mathrm{~kg}^{-1}$ at a power density of $1680 \mathrm{~W} \mathrm{~kg}^{-1}$, which is much greater than that in $6 \mathrm{M} \mathrm{KOH}\left(21.1 \mathrm{~W} \mathrm{~h} \mathrm{~kg}^{-1}\right.$ at $491 \mathrm{~W}$ $\left.\mathrm{kg}^{-1}\right)$. These results show that PCMFs derived from the tamarind seed coat are favorable materials for high-performance SCs with large power and energy densities.

The rationale behind these superior properties can be attributed to the material structure and composition increasing the mechanical stability as well as electronic conductivity through their fibrous pathway. The 3D fibrous structure seen from the electron microscopic results show interconnected polygonal particles which can provide a low-resistance pathway for the electron transfer. Further, the void space between the polygonal particles allows more volume for the electrolyte, which can lower the ion transfer resistance. This combination of the hierarchical structure with the partial graphitic nature identified by XRD, in corroboration with the micro-mesopore data, is favorable for SC electrode applications. The high rate capability makes this material suitable for high-power SC applications.

\section{CONCLUSIONS}

The synthesis of hierarchical PCMFs was reported. The raw materials chosen for HPC are easily available and the making process is amenable for large-scale production. The criterion for choosing these materials is their higher polyphenol content.
Tamarind seed coats were used as the carbon precursor, which forms the natural template to facilitate the formation of wellstructured carbon microfibers, without any expensive surfactants. The effect of the chemical activating agent concentration on the specific surface area and porosity was carefully studied. The highest surface area was obtained for the sample treated with a concentration of $3(\mathrm{KOH})$ at $800{ }^{\circ} \mathrm{C}$. The synthesized PCMF-3 possesses superior capacitance in both $6 \mathrm{M} \mathrm{KOH}$ and BmIm-TFSI electrolytes with excellent cyclic stability. High specific capacitances of $157 \mathrm{~F} \mathrm{~g}^{-1}$ in $6 \mathrm{M} \mathrm{KOH}$ and $76 \mathrm{~F} \mathrm{~g}^{-1}$ in BmIm-TSFI at a current density of $0.5 \mathrm{~A} \mathrm{~g}^{-1}$ are achieved. With the large voltage offered by the IL electrolyte, the PCMF3 electrode can store/release high maximum energy of 119.2 $\mathrm{W} \mathrm{h} \mathrm{kg}-1$ at a power density of $1.68 \mathrm{~kW} \mathrm{~kg}^{-1}$. These findings suggest that the pore size between 1.5 and $2.5 \mathrm{~nm}$ is essential to obtain a high specific capacitance in an IL electrolyte, which has a bulky anion like TFSI. The well-developed porous structure on the carbon microfibers was found to be the key factor for enhancement in the SC performance. A mere increase in microporosity would not contribute to the increase in capacitance as well as retention capacity. The work reported here provides an attractive route for the production of microstructural carbon materials through the transformation of low cost, abundant, and renewable biomass for SC electrode applications.

\section{EXPERIMENTAL SECTION}

Materials. Export quality tamarind seeds were procured as samples from a reliable vendor at Chennai, India. All other chemicals were utilized without purification. Deionized water was used throughout the experiments.

Material Preparation. Tamarind seeds were procured from a local market in Chennai, India. The tamarind seeds were cleaned and washed with deionized water until the filtrate was clear. The tamarind seeds were subjected to a preparatory method as described elsewhere. ${ }^{48}$ Briefly, 2 g of the seed coat powder dispersed in $60 \mathrm{~mL}$ of deionized water was hydrothermally carbonized at $250{ }^{\circ} \mathrm{C}$. Later, it was subjected to high-temperature carbonization to obtain a carbon microfiber.

In this research, we have activated the carbonized fiber using a facile scheme, wherein the carbonized fiber was mixed with $\mathrm{KOH}$ in the weight ratio of $1: 1,1: 2$, and $1: 3$ in deionized water and stirred continuously. The resultant mixture was dried at $100{ }^{\circ} \mathrm{C}$ and then activated at $800{ }^{\circ} \mathrm{C}$ for $1 \mathrm{~h}$ in the flow of argon gas at a ramp rate of $5{ }^{\circ} \mathrm{C} \mathrm{min}^{-1}$. The final product was washed with deionized water several times and dried at $100^{\circ} \mathrm{C}$. 
The chemically activated sample has been labeled as PCMF- $x$ (PCMFs), where $x$ is the $\mathrm{KOH}$ weight ratio.

Characterization. The morphology of the prepared samples was characterized by SEM (Hitachi S-4800). The FESEM images were obtained with Carl Zeiss Merlin FESEM at an operating voltage of $5 \mathrm{kV}$. The TEM images were obtained on a FEI Tecnai G2 microscope, and the samples were dispersed in ethanol and dropped on a copper grid. The XRD patterns were recorded on a Rigaku-SmartLab X-ray diffractometer with $\mathrm{Cu} \mathrm{K} \alpha$ radiation $(\lambda=1.5418 \AA)$ operating at $40 \mathrm{kV}, 30 \mathrm{~mA}$. The data were collected from $10^{\circ}$ to $90^{\circ}$ with the scan rate of $30 \mathrm{~min}^{-1}$ and steps of 0.02 . The nitrogen adsorption-desorption measurements of the samples were carried out at $-196{ }^{\circ} \mathrm{C}$, and the surface area $\left(S_{\mathrm{BET}}\right)$ values were calculated using the standard Brunauer-Emmett-Teller (BET) equation (Micromeritics ASAP 2020). The total pore volume $\left(V_{\text {total }}\right)$ of the samples was calculated at the maximum relative pressure of $P / P_{0}=0.995$. The micropore $\left(V_{\text {micro }}\right)$ and mesopore $\left(V_{\text {meso }}\right)$ volumes were calculated using the DubininRadushkevich analysis.

Electrochemical Characterization in $6 \mathrm{M} \mathrm{KOH}$. The electrode was prepared by mixing active carbon materials, acetylene black, and poly(tetrafluoroethylene) in a weight ratio of 10:1:1 in 1-propanol to obtain a paste. The paste was then pressed onto a Ni mesh area of $1 \mathrm{~cm}^{2}$ and air-dried at $80{ }^{\circ} \mathrm{C}$ for $12 \mathrm{~h}$. A two-electrode cell for SC application has been assembled by taking two identical electrodes made from the hierarchical PCMFs derived from the tamarind seed coat, separated using a polypropylene membrane, and nickel mesh was used as the current collector, which was clipped between two poly(ethylene terephthalate) plates.

Electrochemical Characterization in IL. To measure the symmetric SC using the IL electrolyte, the electrodes have been prepared by spray-coating the slurry containing active materials, conducting carbon, and binder in the ratio of 10:1:1 on an aluminum current collector. Two identical electrodes were separated by a polypropylene separator soaked in the BmIm-TFSI electrolyte in a HS-type cell.

The cyclic voltammetry and GCD tests were conducted using a Solartron (Model-1400) electrochemical workstation in $6 \mathrm{M} \mathrm{KOH}$ and BmIm-TFSI to evaluate the capacitance performance. The specific capacitance $(C)$ of a symmetric capacitor has been calculated using the following equation ${ }^{43}$

$$
C=2 \frac{I \cdot \Delta t}{m \cdot \Delta V}
$$

where, " $I$ " is the discharge current (A), " $\Delta V$ " is the change in voltage within the discharge time $(\mathrm{V})$, " $\Delta t$ " is the discharge time (s), and " $m$ " is the mass of each electrode $(\mathrm{g})$. The energy density and power density of the symmetrical SC have been calculated from the following equation ${ }^{43}$

$$
\begin{aligned}
& \text { Energy density }=\frac{C V^{2}}{2 \times 3.6} \\
& \text { Power density }=\frac{E}{\Delta t}
\end{aligned}
$$

where " $V$ " is the discharge voltage $(\mathrm{V})$ and " $\Delta t$ " is the discharging time $(\mathrm{h})$.

\section{ASSOCIATED CONTENT}

\section{S Supporting Information}

The Supporting Information is available free of charge on the ACS Publications website at DOI: 10.1021/acsomega. 8 b01850.

FESEM images of chemically activated samples; XRD patterns of all samples; cyclic voltammetry and GCD curves of all the samples in the $6 \mathrm{M} \mathrm{KOH}$ and IL electrolytes (PDF)

\section{AUTHOR INFORMATION}

\section{Corresponding Author}

*E-mail: rajalakshmi@arci.res.in. Phone: +91-044-66632707. ORCID

N. Rajalakshmi: 0000-0002-4698-416X

Notes

The authors declare no competing financial interest.

\section{ACKNOWLEDGMENTS}

The authors would like to acknowledge Dr. Raman Vedarajan for editing this manuscript and Dr. G. Padmanabham, Director, and Dr. R. Gopalan, Associate Director, ARCI for their continuous support and encouragement.

\section{REFERENCES}

(1) Tan, H.; Wang, X.; Jia, D.; Hao, P.; Sang, Y.; Liu, H. Structuredependent electrode properties of hollow carbon micro-fibers derived from Platanus fruit and willow catkins for high-performance supercapacitors. J. Mater. Chem. A 2017, 5, 2580-2591.

(2) Wahid, M.; Parte, G.; Phase, D.; Ogale, S. Yogurt: a novel precursor for heavily nitrogen doped supercapacitor carbon. J. Mater. Chem. A 2015, 3, 1208-1215.

(3) He, S.; Hu, Y.; Wan, J.; Gao, Q.; Wang, Y.; Xie, S.; Qiu, L.; Wang, C.; Zheng, G.; Wang, B.; Peng, H. Biocompatible carbon nanotube fibers for implantable supercapacitors. Carbon 2017, 122, $162-167$.

(4) Yang, L.; Hou, L. R.; Zhang, Y. W.; Yuan, C. Z. Facile synthesis of mesoporous carbon nanofibres towards high-performance electrochemical capacitors. Mater. Lett. 2013, 97, 97-99.

(5) Wang, D.; Xu, L.; Wang, Y.; Xu, W. Rational synthesis of porous carbon nanocages and their potential application in high rate supercapacitors. Electroanal. Chem. 2018, 815, 166-174.

(6) Xing, B.; Yuan, R.; Zhang, C.; Huang, G.; Guo, H.; Chen, Z.; Chen, L.; Yi, G.; Zhang, Y.; Yu, J. Facile synthesis of graphene nanosheets from humic acid for supercapacitors. Fuel Process. Technol. 2017, 165, 112-122.

(7) Zhang, G.; Chen, Y.; Chen, Y.; Guo, H. Activated biomass carbon made from bamboo as electrode material for supercapacitors. Mater. Res. Bull. 2018, 102, 391-398.

(8) Hao, P.; Zhao, Z.; Tian, J.; Li, H.; Sang, Y.; Yu, G.; Cai, H.; Liu, H.; Wong, C. P.; Umar, A. Hierarchical porous carbon aerogel derived from bagasse for high performance supercapacitor electrode. Nanoscale 2014, 6, 12120-12129.

(9) Balach, J.; Tamborini, L.; Sapag, K.; Acevedo, D. F.; Barbero, C. A. Facile preparation of hierarchical porous carbons with tailored pore size obtained using a cationic polyelectrolyte as a soft template. Colloids Surf., A 2012, 415, 343-348.

(10) Xu, F.; Cai, R.; Zeng, Q.; Zou, C.; Wu, D.; Li, F.; Lu, X.; Liang, Y.; Fu, R. Fast ion transport and high capacitance of polystyrenebased hierarchical porous carbon electrode material for supercapacitors. J. Mater. Chem. 2011, 21, 1970-1976.

(11) Yang, C.-M.; Weidenthaler, C.; Spliethoff, B.; Mayanna, M.; Schüth, F. Facile Template Synthesis of Ordered Mesoporous Carbon with Polypyrrole as Carbon Precursor. Chem. Mater. 2005, 17, 355358. 
(12) Zhang, B.; Wu, Y.; Meng, F.; Xu, T.; Zhu, J.; Sun, M. Preparation and characterization of ordered nanoporous carbon materials by templating method. Procedia Eng. 2012, 27, 762-767.

(13) Luo, H.-M.; Yang, Y.-F.; Sun, Y.-X.; Zhao, X.; Zhang, J.-Q. Preparation of fructose-based attapulgite template carbon materials and their electrochemical performance as supercapacitor electrodes. $J$. Solid State Electrochem. 2015, 19, 1491-1500.

(14) Shi, J.; Li, W.; Li, D. Rapidly reversible adsorption of methane with a high storage capacity on the zeolite templated carbons with glucose as carbon precursors. Colloids Surf., A 2015, 485, 11-17.

(15) Dutta, S.; Huang, S.-Y.; Chen, C.; Chen, J. E.; Alothman, Z. A.; Yamauchi, Y.; Hou, C.-H.; Wu, K. C.-W. Cellulose Framework Directed Construction of Hierarchically Porous Carbons Offering High-Performance Capacitive Deionization of Brackish Water. ACS Sustainable Chem. Eng. 2016, 4, 1885-1893.

(16) Liu, Y.; Shi, Z.; Gao, Y.; An, W.; Cao, Z.; Liu, J. BiomassSwelling Assisted Synthesis of Hierarchical Porous Carbon Fibers for Supercapacitor Electrodes. ACS Appl. Mater. Interfaces 2016, 8, 28283-28290.

(17) Liang, C.; Bao, J.; Li, C.; Huang, H.; Chen, C.; Lou, Y.; Lu, H.; Lin, H.; Shi, Z.; Feng, S. One-dimensional hierarchically porous carbon from biomass with high capacitance as supercapacitor materials. Microporous Mesoporous Mater. 2017, 251, 77-82.

(18) You, X.-l.; Liu, L.-j.; Zhang, M.-y.; Walle, M. D.; Li, Y.; Liu, Y.$\mathrm{N}$. Novel biomass derived hierarchical porous carbon for lithium sulfur batteries. Mater. Lett. 2018, 217, 167-170.

(19) Chen, L.; Ji, T.; Mu, L.; Shi, Y.; Wang, H.; Zhu, J. Pore size dependent molecular adsorption of cationic dye in biomass derived hierarchically porous carbon. J. Environ. Manage. 2017, 196, 168-177.

(20) Chen, J.; Zhou, X.; Mei, C.; Xu, J.; Zhou, S.; Wong, C.-P. Evaluating biomass-derived hierarchically porous carbon as the positive electrode material for hybrid Na-ion capacitors. J. Power Sources 2017, 342, 48-55.

(21) Chen, L.; Ji, T.; Mu, L.; Zhu, J. Cotton fabric derived hierarchically porous carbon and nitrogen doping for sustainable capacitor electrode. Carbon 2017, 111, 839-848.

(22) Dutta, S.; Bhaumik, A.; Wu, K. C.-W. Hierarchically porous carbon derived from polymers and biomass: effect of interconnected pores on energy applications. Energy Environ. Sci. 2014, 7, 35743592.

(23) Tian, W.; Gao, Q.; Tan, Y.; Yang, K.; Zhu, L.; Yang, C.; Zhang, $\mathrm{H}$. Bio-inspired beehive-like hierarchical nanoporous carbon derived from bamboo-based industrial by-product as a high performance supercapacitor electrode material. J. Mater. Chem. A 2015, 3, 56565664.

(24) Peng, L.; Liang, Y.; Dong, H.; Hu, H.; Zhao, X.; Cai, Y.; Xiao, Y.; Liu, Y.; Zheng, M. Super-hierarchical porous carbons derived from mixed biomass wastes by a stepwise removal strategy for highperformance supercapacitors. J. Power Sources 2018, 377, 151-160.

(25) Sanchez-Sanchez, A.; Izquierdo, M. T.; Ghanbaja, J.; Medjahdi, G.; Mathieu, S.; Celzard, A.; Fierro, V. Excellent electrochemical performances of nanocast ordered mesoporous carbons based on tannin-related polyphenols as supercapacitorelectrodes. J. Power Sources 2017, 344, 15-24.

(26) Mayes, R. T.; Tsouris, C.; Kiggans, J. O., Jr.; Mahurin, S. M.; DePaoli, D. W.; Dai, S. Hierarchical ordered mesoporous carbon from phloroglucinol-glyoxal and its application in capacitive deionization of brackish water. J. Mater. Chem. 2010, 20, 8674.

(27) Szczurek, A.; Fierro, V.; Pizzi, A.; Stauber, M.; Celzard, A. Carbon meringues derived from flavonoid tannins. Carbon 2013, 65, 214-227.

(28) Szczurek, A.; Fierro, V.; Pizzi, A.; Celzard, A. Emulsiontemplated porous carbon monoliths derived from tannins. Carbon 2014, 74, 352-362.

(29) Bai, C.-X.; Shen, F.; Qi, X.-H. Preparation of porous carbon directly from hydrothermal carbonization of fructose and phloroglucinol for adsorption of tetracycline. Chin. Chem. Lett. 2017, 28, 960-962.
(30) Saha, D.; Warren, K. E.; Naskar, A. K. Soft-templated mesoporous carbons as potential materials for oral drug delivery. Carbon 2014, 71, 47-57.

(31) Ramesh, T.; Rajalakshmi, N.; Dhathathreyan, K. S. Activated carbons derived from tamarind seeds for hydrogen storage. J. Energy Storage 2015, 4, 89-95.

(32) Prabhu, K. H.; Teli, M. D. Eco-dyeing using Tamarindus indica L. seed coat tannin as a natural mordant for textiles with antibacterial activity. J. Saudi Chem. Soc. 2014, 18, 864-872.

(33) Fang, Z.; Sato, T.; Smith, R. L.; Inomata, H. Reaction chemistry and phase behavior of lignin in high-temperature and supercritical water. Bioresour. Technol. 2008, 99, 3424-3430.

(34) Falco, C.; Baccile, N.; Titirici, M.-M. Morphological and structural differences between glucose, cellulose and lignocellulosic biomass derived hydrothermal carbons. Green Chem. 2011, 13, 3273.

(35) Kang, S.; Li, X.; Fan, J.; Chang, J. Characterization of Hydrochars Produced by Hydrothermal Carbonization of Lignin, Cellulose, d-Xylose, and Wood Meal. Ind. Eng. Chem. Res. 2012, 51, 9023-9031.

(36) Cheng, K.-K.; Hsu, T.-C.; Kao, L.-H. A microscopic view of chemically activated amorphous carbon nanofibers prepared from core/sheath melt-spinning of phenol formaldehyde-based polymer blends. J. Mater. Sci. 2011, 46, 3914-3922.

(37) Guo, S.; Dong, X.; Wu, T.; Shi, F.; Zhu, C. Characteristic evolution of hydrochar from hydrothermal carbonization of corn stalk. J. Anal. Appl. Pyrolysis 2015, 116, 1-9.

(38) Fan, Y.; Yang, X.; Zhu, B.; Liu, P.-F.; Lu, H.-T. Micromesoporous carbon spheres derived from carrageenan as electrode material for supercapacitors. J. Power Sources 2014, 268, 584-590.

(39) Zhang, M.; He, C.; Liu, E.; Zhu, S.; Shi, C.; Li, J.; Li, Q.; Zhao, N. Activated Carbon Nanochains with Tailored Micro-Meso Pore Structures and Their Application for Supercapacitors. J. Phys. Chem. C 2015, 119, 21810-21817.

(40) Dong, Y.; Lin, H.; Zhou, D.; Niu, H.; Jin, Q.; Qu, F. Synthesis of mesoporous graphitic carbon fibers with high performance for supercapacitor. Electrochim. Acta 2015, 159, 116-123.

(41) Cai, J.; Niu, H.; Li, Z.; Du, Y.; Cizek, P.; Xie, Z.; Xiong, H.; Lin, T. High-Performance Supercapacitor Electrode Materials from Cellulose-Derived Carbon Nanofibers. ACS Appl. Mater. Interfaces 2015, 7, 14946-14953.

(42) Ganesan, A.; Mukherjee, R.; Raj, J.; Shaijumon, M. M. Nanoporous rice husk derived carbon for gas storage and high performance electrochemical energy storage. J. Porous Mater. 2014, $21,839-847$.

(43) Qu, W.-H.; Xu, Y.-Y.; Lu, A.-H.; Zhang, X.-Q.; Li, W.-C. Converting biowaste corncob residue into high value added porous carbon for supercapacitor electrodes. Bioresour. Technol. 2015, 189, 285-291.

(44) Qian, W.; Sun, F.; Xu, Y.; Qiu, L.; Liu, C.; Wang, S.; Yan, F. Human hair-derived carbon flakes for electrochemical supercapacitors. Energy Environ. Sci. 2014, 7, 379-386.

(45) Ruibin, Q.; Zhongai, H.; Yuying, Y.; Zhimin, L.; Ning, A.; Xiaoying, R.; Haixiong, H.; Hongying, W. Monodisperse carbon microspheres derived from potato starch for asymmetric supercapacitors. Electrochim. Acta 2015, 167, 303-310.

(46) Jain, A.; Tripathi, S. K. Nano-porous activated carbon from sugarcane waste for supercapacitor application. J. Energy Storage 2015, 4, 121-127.

(47) Rufford, T. E.; Hulicova-Jurcakova, D.; Zhu, Z.; Lu, G. Q. Nanoporous carbon electrode from waste coffee beans for high performance supercapacitors. Electrochem. Commun. 2008, 10, 15941597.

(48) Sahu, S. R.; Devi, D. P.; Phanikumar, V. V. N.; Ramesh, T.; Rajalakshmi, N.; Praveena, G.; Prakash, R.; Das, B.; Gopalan, R. Tamarind seed skin-derived fiber-like carbon nanostructures as novel anode material for lithium-ion battery. Ionics 2018, 24, 1-9. 